\title{
Editorial
}

\section{Authorised Health Claims May Not Help Consumers to Choose a Healthy Diet}

\author{
Anne de la Hunty ${ }^{a}$ Margaret Ashwell $^{a} \quad$ Ursula Arens $^{a} \quad$ Sigrid Gibson ${ }^{b}$ \\ Michele Sadler ${ }^{c}$

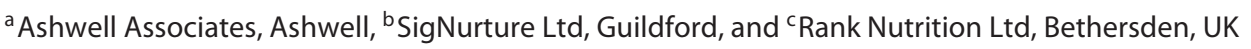

More than 10 years ago, the European Commission proposed a regulation of nutrition and health claims [13]. After agreeing on the procedure for submissions and the terms of reference for the scientific assessment, and setting up the authorisation procedures, the European Union (EU) Register on Nutrition and Health Claims was established, which currently contains opinions on 2,204 submitted health claims, 252 of which have been authorised. Although the main impetus for the regulations was the protection of consumers from unwarranted claims, it was also recognised that health claims should be helpful in choosing a healthy diet $[2,3]$. We have compared the authorised health claims relating to diet and heart health with generally agreed dietary recommendations for the prevention of heart disease as a way of examining whether the regulations can indeed assist consumers in choosing a healthier diet [4].

\section{The Round Table Model of Diet and Heart Disease}

We have used several versions of the Round Table Model of Diet and Heart Disease as a pragmatic tool for the discussion and communication of this complicated topic [5-7]. Figure 1, depicting the model, shows the var-

\section{KARGER}

E-Mail karger@karger.com

www.karger.com/anm ious dietary factors (outer two rings) that have beneficial or adverse effects on the principal physiological risk factors (middle ring) which impact upon the pathological events (inner ring) leading to cardiovascular disease. A general yellow ring, described as 'less controllable factors' is positioned between the physiological and dietary factors to indicate the differences observed between people with regard to genetic factors [8], early-life factors [9] and the distribution of body fat [10].

The scientific basis for the inclusion of the dietary factors in the outer two rings in figure 1 is the WHO report on Diet, Nutrition and the Prevention of Chronic Diseases [11]. Although this report is now 10 years old, it still represents the most comprehensive and authoritative review of the impact of dietary factors on heart health and is still used as the basis for healthy eating advice given by many health professionals. Table 10 of this WHO report summarised the strength of the evidence of factors (foods and food components/nutrients) contributing to the risk for developing cardiovascular diseases with the terms 'convincing', 'probable', 'possible' and 'insufficient'. We have included all grades of evidence here except 'insufficient' and have only distinguished between 'convincing' and 'probable' (in regular type) and 'possible' (in italics). For all except three (c) 2014 S. Karger AG, Basel

0250-6807/14/0641-0001\$39.50/0
Dr. Margaret Ashwell, OBE

Ashwell Associates, Ashwell Street Ashwell, Hertfordshire SG7 5PZ (UK)

E-Mail margaret@ ashwell.uk.com 
- Foods and food components to increase in black CAPITALS

- Foods and food components to reduce in black lower case

- WHO convincing or probable evidence in regular case; possible evidence in italics

Abbreviations

LA, linoleic acid: ALA alpha linolenic acid, EPA, eicosapentaenoic acid; DHA, docosahexaenoic acid; NSP, non-starch polysaccharides.

Round Table Model @ Dr. Margaret Ashwell, OBE

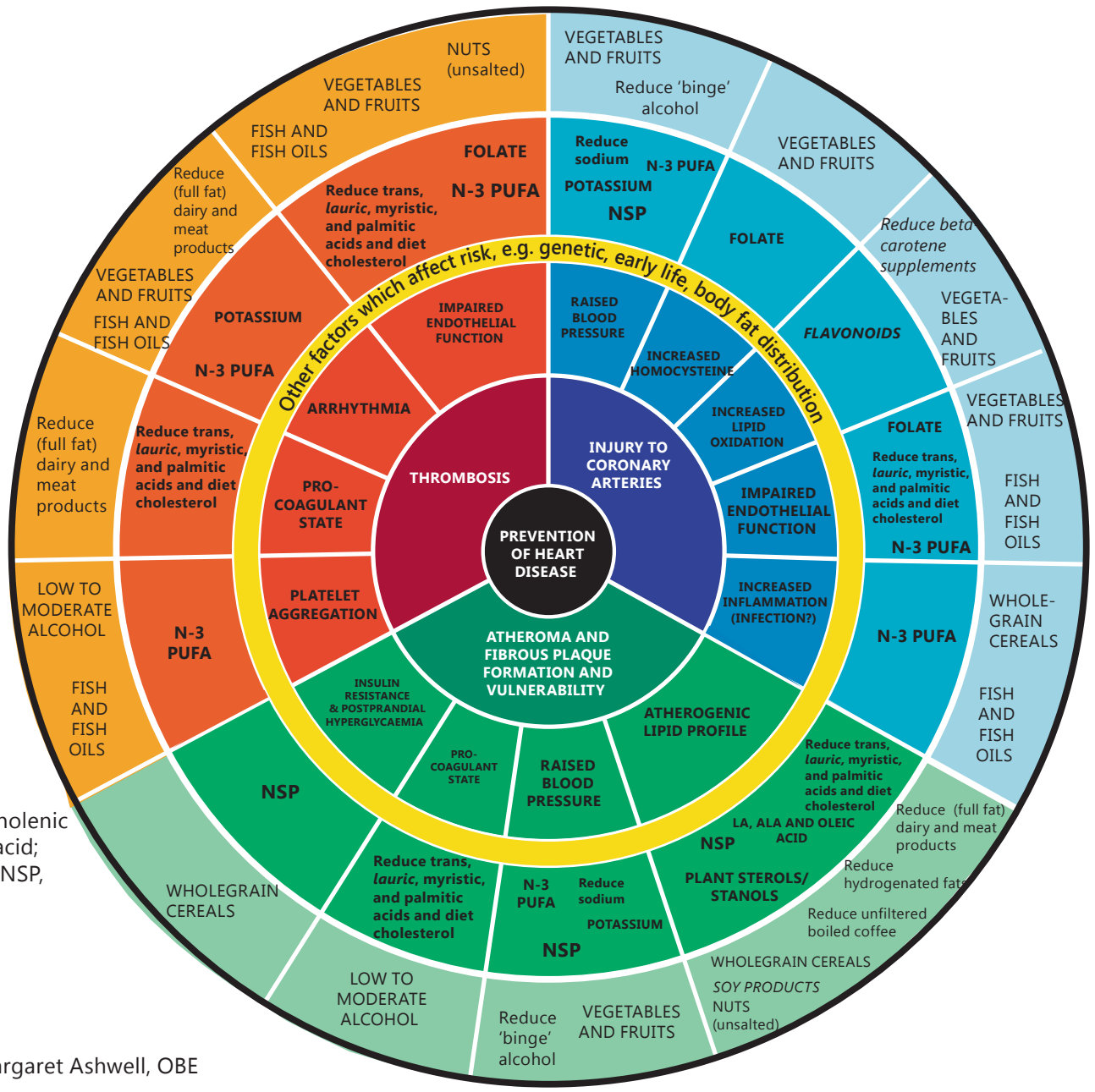

Fig. 1. A round table of dietary factors related to heart disease, incorporating WHO 2003 recommendations.

dietary factors, the evidence was considered 'convincing or probable'. As the WHO report did not specify mechanisms of action for all components, we used our knowledge of accepted links with physiology and pathology to allocate some food components to particular sections in the round table.

\section{EU-Authorised Health Claims Related to Heart Health}

The initiative for consideration of the scientific validity of health claims is the submission of a dossier/supporting references by a food company, or ingredient or prod- uct sector group for scientific assessment by the European Food Safety Authority (EFSA) [12]. EFSA has not undertaken a systematic review of all the literature relating to diet and heart disease and so takes a reactive approach to the evidence rather than the proactive approach taken by the WHO. The basis for EU authorisation of health claims is the positive outcome of the critical assessment of three key aspects of health claims: (1) adequate characterisation of the food or food component, (2) the claimed effect represents a beneficial physiological effect (general function claims) or an independent risk factor for development of a disease (reduction of disease risk claims) and (3) the scientific evidence base for the claim demonstrates a 
- EU article 13.1 or 13.5 claims in regular case

- EU Article 14.1 claims in italics

Abbreviations SFA, saturated fatty acids: MUFA, monounsaturated fatty acids; PUFA polyunsaturated fatty acids; LA, linoleic acid: ALA alpha linolenic acid: HPMC, Hydroxypropyl methylcellulose; EPA, eicosapentaenoic acid; DHA, docosahexaenoic acid; SDS slowly digestible starch

Round Table Model (c Dr. Margaret Ashwell, OBE

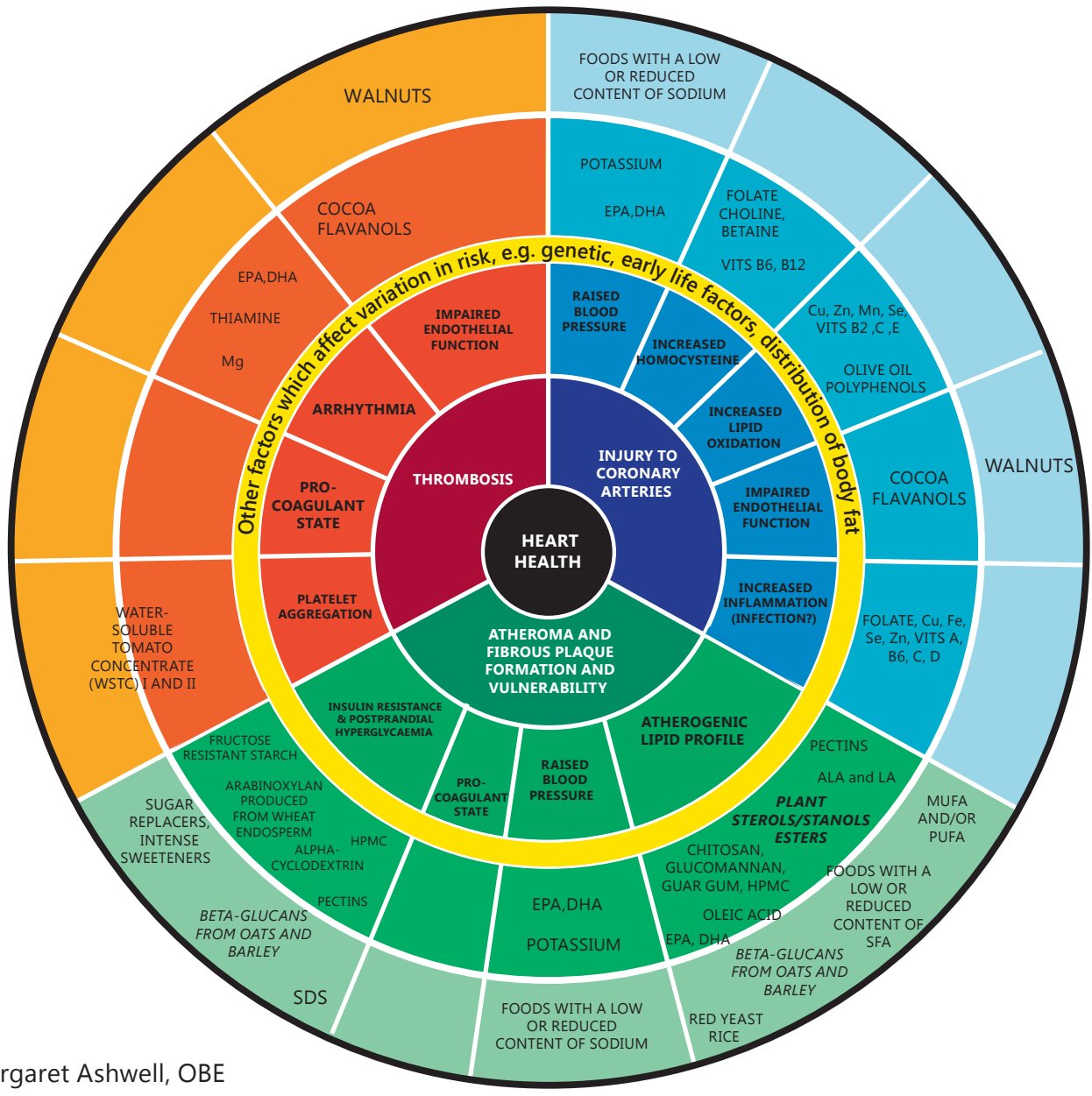

Fig. 2. EU-authorised claims related to heart health, as of October 2013.

cause and effect relationship. EFSA does not accept epidemiological evidence alone as being sufficient to substantiate a health claim. This is in contrast with the approach used by WHO/FAO, which did not require evidence from randomised controlled trials to grade evidence as convincing, provided there was a substantial number of consistent prospective observational studies and biological plausibility.

We searched the EU Register of Health Claims using the foods, nutrients and physiological factors in the WHO-based model as search terms. The authorised claims for nutrient/foods, related to beneficial physiological effects or to independent risk factors for heart disease, were then mapped onto the Round Table Model (see fig. 2). It should, however, be noted that EFSA's determination of physiological risk factors is particularly strict and they are defined as independent predictors of disease risk supported by a biologically plausible mechanism [13]. Though we have retained the 'physiological risk factor' ring, many of these factors do not have sufficiently strong evidence to be considered as independent risk factors by EFSA. Thus, they mostly represent beneficial physiological effects as distinct from risk factors. 


\section{How Do Prudent Dietary Recommendations for the Prevention of Cardiovascular Disease and EU-Authorised Claims Related to Heart Health Compare?}

The most striking feature of the two models is how little overlap there is between them. Not surprisingly perhaps, the two physiological risk factors which show the greatest similarity in terms of the food components mapped onto them are the maintenance of normal cholesterol levels (included in the atherogenic lipid profile) and the maintenance of normal blood pressure. For both these risk factors, there are three common nutrient/diet factors included in both the WHO-based model (fig. 1) and the EU Claims Register model (fig. 2). However, even in these areas, there are differences in the way the relationship is expressed. All the EU-authorised claims are for components and foods with beneficial effects on heart health, so that, for example, rather than saying 'reduce sodium' as in the WHO-based model, the authorised health claim is for foods with a low or reduced content of sodium.

The main difference between the two is that many more dietary factors are included in the WHO-based model while the authorised health claims give the impression of a more restricted range of dietary factors affecting heart health. Perhaps the most surprising omissions in the food ring of figure 2 are authorised claims for vegetables and fruit, fish and fish oils and wholegrain cereals. Submissions were made to EFSA, but the claims were rejected on the grounds that either these food groups were not sufficiently characterised or that the claimed effect was not substantiated. In contrast, WHO had concluded that the evidence for a protective effect of vegetables and fruit and fish and fish oils was convincing and was probable in the case of wholegrain cereals. A claim for soy products, included in the WHO-based model as possibly decreasing risk, was also rejected by EFSA on the grounds that the claimed effect was not substantiated.

In addition, there are authorised claims for foods/food components/nutrients which were either not included in the WHO report or for which the evidence was considered to be insufficient. There are authorised claims that vitamin $\mathrm{C}$ and vitamin $\mathrm{E}$ protect lipids from oxidative damage. This could, in theory, suggest that they also reduce the risk of cardiovascular disease, but this has not been found to be the case in some trials. WHO concluded that there was convincing evidence that vitamin E supplements have no effect on risk and insufficient evidence to say that vitamin $\mathrm{C}$ decreases risk. For other components, such as beta glucans from oats and barley, their absence from the WHO report might be because some of the evidence has only accumulated since the report was published. Other authorised EU claims, however, relate to very minor components of the diet such as food ingredients that can be consumed only as specifically formulated functional foods or food supplements (for example betaine, choline, chitosan and pectins) or specific foods such as red yeast rice (a traditional Chinese food which contains the active ingredient, monacolin $\mathrm{K}$ ) and water-soluble tomato concentrate.

\section{Conclusions}

Our comparison between the dietary components which are included in the WHO Round Table Model of Heart Health (fig. 1) and those which have EU-authorised health claims relating to heart health (fig. 2) highlighted many differences. This raises the issue of the overall balance of the diet being promoted by authorised health claims. Minor components of the diet such as red yeast rice and chitosan are given undue prominence just because they have an authorised claim whereas major components of the diet such as vegetables and fruit do not. We fear that consumers using health claims only as a guide would not end up consuming what is generally recognised as a healthy diet. This raises questions about how well the Nutrition and Health Claims Regulation is able to assist consumers in this choice. While there is a legitimate debate to be had about how evidence should be graded and what should constitute convincing evidence for the purposes of population risk reduction, we are concerned that the disparity in outcome between the two evaluation processes threatens to undermine the credibility of both and may confuse consumers (and perhaps health professionals). Our view is that the health claims approval process is currently tilted too much towards the protection of the consumer from unwarranted health claims and not enough towards empowering consumers to choose a healthier diet.

References

1 European Commission: Proposal for the $\mathrm{Nu}$ trition and Health Claims Regulation. Vol. Proposal No. COM 424, 2003.

2 European Union: Regulation (EC) No. $1924 / 2006$ of the European Parliament and of the Council of 20 December 2006 on nutrition and health claims made on foods. Off J Eur Union 2006;L404.
4
Ann Nutr Metab 2014;64:1-5 DOI: $10.1159 / 000356127$ de la Hunty/Ashwell/Arens/Gibson/ Sadler 
3 European Union: Corrigendum to Regulation (EC) No. 1924/2006 on Nutrition and Health Claims made on Foods. Off J Eur Union 2007;L12/3.

4 Ashwell M, Arens U, Gibson S, de la Hunty A, Sadler M: A challenge to nutrition communicators: some mismatch between food label claims and heart health 'round table' messages. Netw Health Diet Mag 2013;88:12-15 (www.nhdmag.com)

5 Ashwell M (ed): Diet and Heart Disease: A Round Table of Factors. London, British Nutrition Foundation, 1993.
6 Ashwell M (ed): Diet and Heart Disease: A Round Table of Factors. London, Chapman \& Hall, 1997.

7 Ashwell M, Hardman A, Oliver M: Cardiovascular disease risk: a round table approach. How do factors related to diet, obesity, activity and drugs contribute to a combined strategy for prevention? Proc Nutr Soc 2000;59: 415-416.

8 Thanassoulis G, Vasan R: Genetic cardiovascular risk prediction: will we get there? Circulation 2010;122:2323-2333.

9 British Nutrition Foundation: Nutrition and Development: Short- and Long-Term Consequences for Health. Chichester, Wiley-Blackwell, 2013.
Ashwell M: Shape: the waist-to-height ratio is a good, simple screening tool for cardiometabolic risk. Nutr Today 2011;46:85-89.

$11 \mathrm{WHO} / \mathrm{FAO}$ Expert Consultation: Diet, nutrition and the prevention of chronic diseases. Geneva, World Health Organization, 2003.

12 Sadler M (ed): Foods, Nutrients and Food Ingredients with Authorised EU Health Claims. Cambridge, Woodhead, in press.

13 EFSA: General guidance for stakeholders on the evaluation of Article 13.1, 13.5 and 14 health claims. EFSA J 2011;9:2135. 